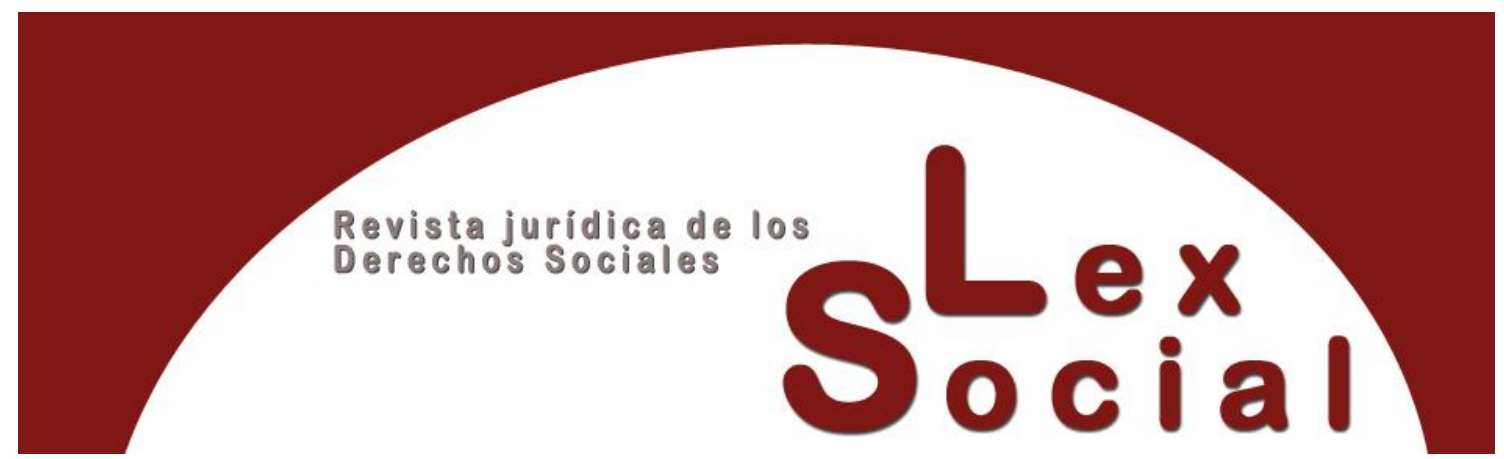

\title{
LA DESIGUALDAD MARCADA POR EL TRATAMIENTO DUAL DEL SERVICIO DE AYUDA A DOMICILIO EN EL MARCO NORMATIVO ESPAÑOL
}

\section{INEQUALITY IN THE DUAL TREATMENT OF THE HOME HELP/CARE SERVICE IN THE SPANISH REGULATORY FRAMEWORK}

\author{
NATALIA ORDÓÑEZ PASCUA \\ Profa. Contratada Doctora \\ Área del Derecho del Trabajo y de la Seguridad Social \\ Universidad de León \\ https://orcid.org/0000-0002-2930-2323
}

Cómo citar este trabajo: Ordoñez Pascua, N. (2021). La desigualdad marcada por el tratamiento dual del servicio de ayuda a domicilio en el marco normativo español. Lex Social: Revista De Derechos Sociales, 11 (2), $729-757$. https://doi.org/10.46661/lexsocial.5966

\begin{abstract}
RESUMEN
En un escenario claramente marcado por el envejecimiento poblacional, suscita un superior interés la necesidad de incrementar la intervención e implicación de los poderes públicos mediante una adecuada oferta de servicios sociales de proximidad que presten apoyo a los colectivos más vulnerables. Entre varios, el servicio de ayuda a domicilio constituye uno de los de mayor demanda por el atractivo inherente a sus características, al tratarse de un servicio público cuya prestación se produce en el propio domicilio del usuario y que engloba aspectos de carácter preventivo, técnico y rehabilitador. Sin embargo, en el marco legítimo del desarrollo competencial propio autonómico subyacen diferencias territoriales en la prestación de un servicio que, a su vez, tiene un doble anclaje en el ámbito asistencial, marcando diferencias de intensidad y servicios cuando su vía de acceso queda se encuentra al margen de la Ley de Dependencia.
\end{abstract}

\section{(cc) BY-NC-SA}


Palabras Clave: servicios públicos, servicios sociales, discapacidad dependencia, ayuda a domicilio.

\begin{abstract}
In a context clearly marked by population ageing, the need to increase the intervention and involvement of public authorities through an adequate supply of close social services that support the most vulnerable groups is of greater interest. Among several, the home support service is one of the most demanded for the inherent attractiveness of its characteristics, since it is a public service whose provision occurs at the user's own home and which encompasses aspects of a preventive, technical and rehabilitative nature. However, within the legitimate framework of self-economic competitive development, territorial differences lie in the provision of a service which, in turn, has a double anchorage in the field of care, marking differences in intensity and services when its access route is outside the Dependency Law.
\end{abstract}

KEYWORDS: public services, public policies, social services, disability, dependence, home care.

\title{
SUMARIO
}

\section{Introducción.}

II. El valor de la protección social de la dependencia en el Estado de bienestar.

III. La asistencia social en el contexto de la Ley de Dependencia.

IV. Servicios Sociales de proximidad: el servicio de ayuda a domicilio y su labor social.

1. Configuración de la prestación básica del Servicio de Ayuda a Domicilio en el marco de los servicios sociales.

2. La prestación especializada del Servicio de Ayuda a Domicilio.

V. El declive de la financiación del SAD: una muerte anunciada de los Planes Concertados de Prestaciones Básicas de Servicios Sociales y otras formas de sostenibilidad.

1. El servicio de comida a domicilio.

2. El Bono Respiro y programas afines.

VI. Conclusiones.

VII. Bibliografía.

VIII. Referencias normativas. 


\section{Introducción}

La atención a las personas en situación de dependencia y la promoción de su autonomía personal constituye uno de los principales retos que ha de afrontar la política social ante la necesidad de atender las demandas de cuantos, por encontrarse en situación de especial vulnerabilidad, requieren apoyos para desarrollar las actividades esenciales de la vida diaria, alcanzar una mayor autonomía personal y poder ejercer plenamente sus derechos de ciudadanía. De hecho, se trata de una cuestión integrada en los sistemas modernos de protección social de gran parte de los países europeos dada la necesidad de afrontar de una manera positiva el envejecimiento activo de la población ante un evidente cambio demográfico y social que no hace sino constatar un incremento progresivo de la población en situación de dependencia.

Esta integración, sin embargo, ha venido "forzada" por el incremento de la población de más de 65 años y por el aumento del colectivo formado por cuantos alcanzan una edad superior a los 80 años, aumentando potencialmente el número de posibles usuarios de la dependencia en las últimas etapas de la vida. De otra parte, es preciso destacar la clara correlación existente entre la edad y las situaciones de discapacidad, conformando una realidad derivada del envejecimiento ${ }^{1}$, a la que hay que añadir las situaciones de dependencia por razón de enfermedad y/u otras causas de discapacidad o limitación cambios producidos en las tasas de supervivencia de determinadas enfermedades crónicas y alteraciones congénitas - así como las consecuencias derivadas de los índices de siniestralidad vial y laboral.

En este contexto ve la luz en el panorama normativo español la Ley 39/2006, de 14 de diciembre, de Promoción de la Autonomía Personal y Atención a las personas en situación de dependencia (LD) con el claro propósito de abordar las necesidades de atención cada vez más demandadas a través de un sistema de prestaciones y/o servicios cuyos beneficiarios se encuentran relacionados en el art. 5 de la propia norma como aquellos que, reuniendo los requisitos legales exigidos respecto a nacionalidad o residencia, se encuentren en situación de dependencia en alguno de los grados establecidos, ofreciendo un tratamiento diferenciado sustentado en razones de edad - menores de 3 años- que requiere estar a lo dispuesto en la Disposición Adicional 13 ${ }^{\mathrm{a}}$ dela LD.

De entre los servicios garantizados por la norma, la atención domiciliaria es uno de los de mayor relevancia en la vertebración del sistema de cuidados de larga duración y por las características que ostenta constituye uno de los servicios de superior demanda, hecho que se manifiesta en la proporción del gasto público que se le dedica y que oscila, dependiendo del país, entre una quinta parte y las tres cuartas partes del gasto total en servicios para personas dependientes ${ }^{2}$.

${ }^{1}$ CORDERO GORDILLO, V.: "Edad y discapacidad", en AA.VV. (CARDONA RUBERT, M ${ }^{\mathrm{a}}$ B.; FLORES GIMÉNEZ, F.; Y CABEZA PEREIRO, J., Coords.): Edad, discriminación y derechos, Monografías Aranzadi, Cizur Menor (Thomson Reuters), 2019, págs. 138-208.

${ }^{2}$ HUBER, M. et allí.: "Expenditure and financing", en AA.VV.: Facts and figures on long-term care. Europe and North America, Viena (European Centre for Social Welfare Policy and Research), 2009, pág. 99. 


\section{El valor de la protección social de la dependencia en el Estado de bienestar}

El Estado social o de bienestar no puede ser concebido sin su imbricación en el concepto de Seguridad Social pues aquél no es más que un conjunto de instituciones sociales ensambladas con el propósito de lograr una mayor prosperidad integral del ciudadano. Aparece así indisolublemente unido a otros de no menor importancia como son el de la protección social y laboral y engarza con la norma de Derecho del Trabajo y de la Seguridad Social.

Su reconocimiento parte de la satisfacción de un conjunto formado por los llamados Derechos Sociales unidos de manera indefectible al principio de justicia social y el trabajo decente. Precisamente la Seguridad Social — como manifestó el gran jurista francés Paul Durand-, como rama o sector diferenciado dentro del ordenamiento jurídico general, va mucho más allá de su entendimiento como conjunto de normas o reglamentaciones desprovistas de principios y de ideas globalizadoras y constructivas y necesita para su comprensión y explicación de las dimensiones políticas, jurídicas, económicas, sociológicas y demográficas, utilizando una metodología interdisciplinar donde se inserta lo jurídico y, analizando a la vez, con la misma atención su función correctiva y preventiva de los riesgos sociales, investigando en todos esos campos con una completa seguridad y rigor técnico. En este sentido, se trataría de "un instrumento de protección social pública diferente a los Seguros sociales a los que sustituye y desplaza por una concepción más amplia de las situaciones de riesgo y necesidad social"3.

Sustentado en el referente ofrecido por los arts. 25 de la Declaración Universal de los Derechos Humanos (ONU, 1948) y 14 de la Carta Social Europea (1961) en cuanto al reconocimiento del derecho a los servicios sociales como proveedores de bienestar a la ciudadanía, la configuración del modelo de bienestar social español descansa sobre la elaboración de un sistema público, en el marco de las leyes autonómicas de servicios sociales y del Plan Nacional Concertado entre las Administraciones Públicas para financiar y prestar asistencia técnica al desarrollo de sus "prestaciones básicas", capaz de dar contenido a los derechos más elementales universales en materia de sanidad, educación, una política de rentas no contributivas, y en servicios sociales.

Fiel reflejo de la situación descrita es el contenido de la Constitución Española de 1978 (CE) al respecto, en cuyo tenor lo "social" constituye un valor reiterativo a lo largo de su articulado, desde la propia definición del Estado como "social y democrático de Derecho" (art. 1.1 CE) hasta el establecimiento de un Título que bajo la denominación "Principios Rectores de la Política Económica y Social" procede a un acopio de los derechos de carácter social (exceptuando el derecho a la educación que sitúa en un capítulo específico) y entre los que se encuentran - por cuanto aquí interesa- varios preceptos que desarrollan el concepto del Estado social a través de la mención a diversos colectivos -

\footnotetext{
${ }^{3}$ VIDA SORIA, J.: "Estudio preliminar sobre la recuperación de un clásico de la doctrina de la Seguridad Social", incluido en la versión española, a cargo del propio autor del libro, DURAND, P.: La política contemporánea de Seguridad Social, Madrid (Ministerio de trabajo y Seguridad Social), 1991, págs. 114 a 116.
} 
familias, jóvenes, personas con discapacidad, personas mayores - y otras referencias al compromiso de los poderes públicos en el progreso social y económico (art. 40), así como "el mantenimiento de un régimen público de Seguridad Social para todos los ciudadanos que garantice la asistencia y prestaciones sociales suficientes ante situaciones de necesidad, especialmente, en caso de desempleo" (art.41 CE). De entre los supra mencionados, el de aquellos de mayor edad es el único que disfruta de una referencia expresa al sistema de los servicios sociales cuando se emplaza a los poderes públicos a garantizar su suficiencia económica mediante pensiones adecuadas y periódicamente actualizadas y a promover su bienestar "mediante un sistema de servicios sociales que atenderán sus problemas específicos de salud, vivienda, cultura y ocio", si bien es cierto que, a lo largo de toda la norma fundamental, subyace la existencia de un sistema público de servicios sociales que se erige como uno de los pilares del Estado de bienestar.

Pese al extenso reconocimiento de derechos referido, aparece un gran factor de tensión en tanto en los principios enunciados se consagran mandatos a los poderes públicos que no dejan sino de "informar la legislación positiva" junto a un elenco de derechos subjetivos como, y así se recoge literalmente, el derecho a una vivienda digna y adecuada (art. $47 \mathrm{CE}$ ), a la protección de la salud (art. $43 \mathrm{CE}$ ), al acceso a la cultura (art. $44 \mathrm{CE}$ ), o a disfrutar de un medioambiente adecuado (art. $45 \mathrm{CE}$ ), que ofrecen un bajo nivel de garantía debilitando su valor y dando lugar a la calificación de los derechos sociales como derechos minorizados. "Este engranaje jurídico viene a decir que siempre cabrá la posibilidad de interpretar un derecho a la baja, pues en el mejor de los casos se habla de mínimo esencial, abierto a la interpretación, en correlación directa con una política gubernamental de presupuestos, o que sea considerado como mero principio rector indicativo, que no se traduce en un derecho subjetivo exigible ante un juez"4.

En consecuencia, para conseguir el bienestar social han de hacerse reales y efectivas las garantías de derechos sociales básicos para toda la ciudadanía ${ }^{5}$ y para ello es preciso completar la universalización de las prestaciones básicas que ofertan cada uno de los sistemas que se ocupan de las materias afectadas como es la educación, la sanidad, las pensiones, el desempleo y servicios sociales, de entre las cuales, la universalización de la educación y la asistencia sanitaria - esta última con sus idas y venidas - han sido la más precoces, seguidas por aquellas políticas de intervención en materia de pensiones que finalmente fructificaron con el establecimiento de un nivel no contributivo de la Seguridad Social ${ }^{6}$.

En el objetivo de proporcionar ese bienestar a la ciudadanía y hacer efectivo el mandato a los poderes públicos de intervenir en gran parte de las esferas de la realidad social, las políticas públicas — y de entre ellas las de carácter social— constituyen la herramienta

\footnotetext{
${ }^{4}$ CARBONELL APARICI, G.J.: "Los derechos sociales en la Constitución española”, Zerbitzuan: Gizarte zerbitzuetarako aldizkaria/ Revista de servicios sociales, núm. 70, 2020, pág.36.

${ }^{5}$ PISARELLO PRADOS, G.: Los derechos sociales y sus garantías: elementos para una reconstrucción, Madrid (Trotta), 2007, pág. 12 y ss.

${ }^{6}$ LAS HERAS PINILLA, Ma . P.: "El sistema público de servicios sociales: contribución del trabajo social, desafíos, oportunidades y estrategias”, Trabajo Social Hoy, núm. extra.1, 2002, pág. 7 y ss.
} 
fundamental del Estado para crear oportunidades - mediante el establecimiento de mecanismos de equidad y de integración social—, y se erigen en la forma de expresión del contenido específico de los servicios, prestaciones y protecciones sociales; de los modos de financiación para garantizar el acceso de quienes carecen de recursos; del aseguramiento de individuos, familias y grupos contra determinados riesgos; y de la protección a quienes se encuentran en situaciones de vulnerabilidad específicas ${ }^{7}$.

Así, aparece un concepto de política social ligado al compendio de medidas arropadas por recursos financieros y normativos dirigidos a ofrecer servicios en las áreas de salud, educación, seguridad social, vivienda, protección laboral y asistencia a las familias, y de ahí que su contenido esté sujeto a la regulación pública, manteniendo el Estado la titularidad haciendo uso de un sistema de transferencias de competencias o ejecución de servicios ${ }^{8}$.

En el diseño de la prestación de asistencia social hoy institucionalizado y en una clara voluntad del legislador de aproximar los servicios sociales a un ámbito geográfico más cercano, aparece como cuestión nuclear la referida a la configuración territorial y la distribución competencial constitucionalmente establecida y amparada en el art. 148.1.20 $\mathrm{CE}$, permitiendo a la posibilidad del ejercicio de competencias en materia de Asistencia Social de manera exclusiva a las Comunidades Autónomas que así lo recojan en sus Estatutos de Autonomía 9 . Son todas las que han aceptado este reto — con las especialidades de las Ciudades Autónomas de Ceuta y Melilla- y avanzado en la decisión de elaborar sus propias leyes de servicios sociales en las cuales definen sus propios principios orientadores en aras a ofrecer garantías de un sistema de prestaciones y servicios de carácter básico, competencia reiterada en las más recientes reformas estatutarias. Por otra parte, los Estatutos de Autonomía además de recoger la competencia en servicios sociales, establecían la organización territorial y autonómica de tal suerte que aquellos reformados a partir de 2006 (Cataluña, Comunidad Valenciana, Illes Balears, Andalucía, Aragón, Castilla y León y Extremadura) concretan de manera más exhaustiva el contenido de la mentada competencia exclusiva y regulan más escrupulosamente las correspondientes Entidades Locales de su territorio.

El marco descrito no permite - sin embargo- desconocer las previsiones sustentadas en el propio texto constitucional y a cuyo tenor es preciso "garantizar los mismos derechos y obligaciones a todos los españoles en cualquier parte del territorio" (art. 139 CE); para ello, el Estado será el único y en exclusiva el competente para proceder a la regulación de "las condiciones básicas que garanticen la igualdad de todos los españoles en el ejercicio de los derechos y en el cumplimiento de los deberes constitucionales" (art. 149.1.1 ${ }^{\circ} \mathrm{CE}$ ) - en este sentido, es clarificador el tenor de la STC 18/2016, de 4 febrero, que al respecto

\footnotetext{
${ }^{7}$ SUBIRATS HUMET, J.: "El análisis de las políticas públicas", Gaceta sanitaria: Órgano oficial de la Sociedad Española de Salud Pública y Administración Sanitaria, Vol. 15, No. 3, 2001, págs. 259-264.

8 VILA LÓPEZ, L.: "Política social e inclusión social", Revista del Ministerio de Trabajo y Asuntos Sociales (ejemplar dedicado a Asuntos sociales), núm. 35, 2002, págs. 13 a 34.

9 ALEMÁN BRACHO, C.: "Los sistemas de servicios sociales en las Leyes autonómicas de servicios sociales”, Revista Española de Derecho del Trabajo, núm. 152, 2011, pág. 16.
} 
de cuantos se encuentran en situación de dependencia refiere cómo "las competencias autonómicas sobre materias no incluidas en el art. 149.1 CE, aunque se enuncien como competencias exclusivas, no cierran el paso a las competencias estatales previstas en aquel precepto constitucional"- - tratando así de ofrecer la necesaria homogeneidad en el acceso a prestaciones y servicios mediante un conjunto de normas de aplicación en todo el territorio nacional que vendrán a conformar un sistema de mínimos y que cada entidad territorial habrá de garantizar — sino superar- en el ejercicio de sus propias competencias.

Al complejo entramado territorial enunciado es preciso añadir la importancia que las Entidades Locales han tenido a lo largo de estos años en la prestación de los servicios de asistencia social de proximidad. A partir del nuevo sistema de configuración de los primeros ayuntamientos de la democracia tras el proceso electoral del año 1979, las Corporaciones Locales (Municipios, Cabildos insulares y Diputaciones Provinciales y Forales) desarrollan nuevas competencias en el área de la asistencia social y de los servicios sociales. El legislador básico estatal de 1985 quiso incluir, en el elenco de competencias propias que había de atribuirse a los municipios por los legisladores estatal y autonómico, la materia de prestación de servicios sociales y de promoción y reinserción social [art. 25.2.k)], de tal modo que conforme a la Ley reguladora de las Bases de Régimen Local [(Ley 7/1985, de 2 de abril) (LRBRL)], los ayuntamientos deberían tener atribuciones en materia de servicios sociales, quedando en manos de la normativa sectorial estatal y autonómica delimitar el alcance concreto de la misma. Abundando en la materia, algunas Comunidades Autónomas han incrementado, bien a través de las leyes autonómicas de régimen local o bien mediante disposiciones contenidas en la normativa sobre servicios sociales, el alcance de los servicios sociales mínimos obligatorios previsto en la legislación básica estatal ${ }^{10}$.

Por cuanto hace al legislador sectorial estatal, también reconoce competencias en materia de servicios sociales a los municipios como muestra la doble vía del art. 12 de la LD: por un lado, cuando otorga capacidad a las entidades locales para participar en la gestión de los servicios de atención a las personas en situación de dependencia, de acuerdo con la normativa de sus respectivas Comunidades Autónomas y dentro de las competencias que la legislación vigente les atribuye; por otro, mediante la previsión de que estas entidades territoriales puedan "participar en el Consejo Territorial del Sistema para la Autonomía y Atención a la Dependencia en la forma y condiciones que el propio Consejo disponga" (art. 12.2 LD).

La modificación que en la LRBRL operó la Ley 27/2013, de racionalización y sostenibilidad de la Administración Local, con la pretendida eliminación de duplicidades y solapamientos competenciales entre las distintas administraciones, supuso en materia de asistencia social una restricción en el contenido prestacional de los servicios sociales.

\footnotetext{
${ }^{10}$ ALMEIDA CERRADA, M.: "Los desafíos de las políticas y de los servicios sociales municipales: de la superación de las secuelas de la Gran Recesión, a la adaptación a un nuevo entorno socioeconómico", Anuario del Gobierno Local, núm.1, 2017, pág. 157 y ss.
} 
En este sentido, recoge de una manera más concreta entre las competencias propias del municipio en referencia a la cuestión de la Asistencia Social la "evaluación e información de situaciones de necesidad social y la atención inmediata a personas en situación o riesgo de exclusión social" (art. 25.2.e. LRBRL) —en lo que parece una transición de la intervención municipal obligatoria del ámbito puramente prestacional a otro de menor entidad focalizado en la identificación de las situaciones de necesidad asistencial ${ }^{11}$ — así como la prestación de servicios en cuanto a "evaluación e información de situaciones de necesidad social y la atención inmediata a personas en situación o riesgo de exclusión social" en aquellos municipios con población superior a 20.000 habitantes (art. 26.1.c. LRBRL), ambas cuestiones relacionadas con los servicios sociales generales o de atención primaria a prestar en su territorio. En todo caso, el establecimiento de obligaciones mínimas para los municipios siempre deja abierta la vía de la prestación de un mayor número de servicios públicos, siempre que las condiciones presupuestarias y la eficacia administrativa así lo permitan ${ }^{12}$.

\section{La asistencia social en el contexto de la Ley de Dependencia}

El escenario competencial descrito condujo a un panorama muy diverso con la aprobación de normativa - Comunidades Autónomas - y reglamentación - ciudades de Ceuta y Melilla- propia, que ha desembocado en una multiplicidad de sistemas de servicios sociales con sus catálogos, carteras de servicios y prestaciones diferenciadas que ha hecho aún más visible la diversidad y diferencias en los distintos territorios en aspectos vitales como los requisitos de acceso a servicios y prestaciones, o el grado de garantía y cuantía en aquellas de carácter económico, generando la necesidad de establecer un consenso respecto de aquellas garantías que deberán operar como mínimo en todas las Comunidades en materia de Servicios Sociales.

En este contexto, aparece como punto de anclaje de los diversos Sistemas para la Autonomía y Atención a la Dependencia la LD estimulando el avance en el desarrollo de los llamados "derechos de tercera generación", y que se enmarcan dentro del Estado del bienestar ${ }^{13}$, que, pese a las dudas iniciales, respeta el marco competencial descrito siempre con la participación, colaboración y cooperación de las distintas Administraciones Públicas $^{14}$.

\footnotetext{
${ }^{11}$ VELASCO CABALLERO, F.: "Nuevo régimen de competencias municipales en el Anteproyecto de Racionalización y Sostenibilidad de la Administración Local", Anuario de Derecho Municipal 2012, núm. 6, 2013, pág. 39.

12 ARIAS MARTÍNEZ, M ${ }^{a}$. A.: "Las competencias locales en materia de servicios sociales tras la aprobación de la Ley 27/2013, de 27 de diciembre, de racionalización y sostenibilidad de la Administración Local”, Revista de Administración Pública, núm. 194, 2014, págs. 373-410.

${ }^{13}$ ORTIZ WALS, V. y FERRERIRA LUZ, A.: "El Servicio de Ayuda a Domicilio como instrumento de Intervención Social con colectivos en riesgo de exclusión social", Documentos de Trabajo Social, núm. 49, 2011, pág. 235.

${ }^{14}$ JIMÉNEZ LARA, A.: "El Sistema para la Autonomía y la Atención a la Dependencia", Sociedad y Utopía. Revista de Ciencias Sociales, núm. 30, 2007, pág. 148.
} 
Sin embargo, cabe resaltar la falta de perspectiva de una ley que comienza a implementarse sin tener en cuenta el número de potenciales beneficiarios, lo que hizo que la demanda superara las previsiones, especialmente las económicas, así como que la distribución de competencias entre las distintas administraciones pudiera generar desigualdad de trato a las personas dependientes en función de su lugar de residencia. Este conflicto competencial continúa siendo a día de hoy igual de actual, haciendo que en muchas Comunidades Autónomas exista un argumento principal para "desviarse de la norma o reinterpretarla de una manera particular"15.

En todo caso, el Sistema de Atención a la Dependencia ofrecido por esta norma pretende garantizar unos mínimos en el acceso a las prestaciones en todo el territorio nacional, sin perjuicio de la mentada necesaria colaboración interadministrativa con las Comunidades Autónomas y las Corporaciones Locales cuya organización cobra forma en el Consejo Territorial del Sistema, en cuyo seno en 2013 — tras siete años de vigencia de la LD ve la luz un Catálogo de Referencia de Servicios Sociales que viene a completar el contenido del art. $15 \mathrm{LD}$, y que respetando las competencias exclusivas en servicios sociales atribuidas a las Comunidades Autónomas, sea capaz de ofrecer cobertura tanto a nivel económico como de prestacional, suministrando servicios de calidad y sostenibles. En todo caso, es preciso tener en cuenta que, sin perjuicio de la regulación estatal de determinados servicios, la definición y garantía de los mismos es, con carácter general, competencia exclusiva de las Comunidades Autónomas, por lo que estarán establecidos en sus disposiciones legales correspondientes. Este extremo es importante por cuanto los servicios y prestaciones económicas incorporados al Catálogo no generarán derechos subjetivos, sino que conforman un mero elenco referencial sin aplicabilidad directa.

El tenor de la LD si contempla, sin embargo, tres niveles de tutela diferenciados (art. 7 LD) manifestación de este poliédrico sistema competencial; un primer nivel correspondería a la Administración del Estado como garante de un mínimo - dando cumplimiento al contenido de los arts. 139 y $149.1 .1^{\circ} \mathrm{CE}-$; un segundo nivel, sostenido en los Convenios de colaboración y cooperación previstos en la propia norma a celebrar entre las Administración del Estado y las Administraciones Autonómicas; y, por último, un tercer nivel sería de carácter adicional y que corresponde de manera exclusiva y voluntaria a cada ente autonómico ${ }^{16}$.

Con todo, es posible afirmar que el legislador no ha pretendido excederse de sus competencias y ha actuado con precaución en orden a mantener una total libertad normativa a las Comunidades Autónomas a la hora de configurar un servicio de atención a la dependencia con el mero requisito de mantener los mínimos de protección exigidos ${ }^{17}$. El modelo de protección social que la LD ha querido configurar trata la cuestión de la

\footnotetext{
${ }^{15}$ RUIDÍAZ GARCÍA, C.: "La política social de atención a las personas dependientes en España. Balance y perspectivas de la Ley de dependencia”, REDUR 10, 2012, pág. 178.

${ }^{16}$ CAVAS MARTÍNEZ, F.: “Aspectos fundamentales de la Ley de promoción de la autonomía personal y atención a las personas en situación de dependencia”, Aranzadi Social, núm. 13, 2006, pág. 7.

${ }^{17}$ DURÁN BERNARDINO, M.: "La distribución constitucional y legal de competencias en el modelo de protección social a la dependencia”, Aranzadi Social: Revista Doctrinal, vol. 6, núm.8, 2013, pág. 13.
} 
dependencia desde una perspectiva universal, superando esa mera visión asistencial a la cual sólo era posible acceder ante la carencia de recursos y disponiendo un sistema de protección financiado fundamentalmente por la vía impositiva, si bien al margen el sistema público de la Seguridad Social. La prestación supone proveer de atención y cuidados a las situaciones de dependencia, asegurando este servicio a cuantos lo necesitan mediante un sistema en el cual el usuario podrá contribuir a su financiación, ampliando y complementado la insuficiente acción protectora de los actuales servicios sociales. Con estas mimbres, legislador crea el Sistema para la Autonomía y Atención a la Dependencia (SAAD), con la intención de garantizar las condiciones básicas de esa promoción, de prever los niveles de protección, y de asegurar la colaboración y participación de todas las Administraciones Públicas implicadas, desarrollando un modelo de atención integral organizado en distintos niveles.

\section{Servicios Sociales de proximidad: el servicio de ayuda a domicilio y su labor social}

De entre los servicios sociales de proximidad dirigidos a potencial la autonomía personal y de atención a la dependencia, el Servicio de Ayuda a Domicilio constituye uno de los más demandados por sus potenciales usuarios.

Proceder al estudio de un servicio como SAD con las características generales de servicio público que muestra, supone partir de su situación en el marco normativo español y, de manera más concreta, a partir de la entrada en vigor de la CE cuando, por un lado, refiere en el literal de su art. $50 \mathrm{CE}$ el mandato a los poderes públicos de garantizar, mediante pensiones adecuadas y periódicamente actualizadas, la suficiencia económica a los ciudadanos durante la tercera edad y promover su bienestar mediante un sistema de servicios sociales que atenderán sus problemas específicos de salud, vivienda, cultura y ocio; y, por otro, al recoger un principio rector en el art. 49 CE según el cual "los poderes públicos realizarán una política de previsión, tratamiento, rehabilitación e integración de los disminuidos físicos, sensoriales y psíquicos, a los que prestarán la atención especializada que requieran y los ampararán especialmente para el disfrute de los derechos que este Título otorga a todos los ciudadanos".

El verdadero punto de inflexión en el desarrollo del SAD vino dado por la entrada en vigor de la LD en 2007 cuando lo sitúa entre el elenco de servicios sociales destinados a la promoción de la autonomía personal y atención a la dependencia relacionados en el Catálogo de servicios ofrecido en el art. 15 de la supra mencionada norma, llenando de contenido ese primer nivel de protección básico que se muestra preciso aportar a los colectivos de mayor edad o que adolecen de alguna discapacidad cuando reconoce que las personas en situación de dependencia en alguno de los grados establecidos, recibirán servicios de prevención con el objeto de prevenir el agravamiento de su grado y nivel de dependencia, incluyendo esta atención en los programas de ayuda a domicilio. 
El servicio diseñado en la LD nace con la pretensión de contribuir al incremento de la independencia y autonomía del beneficiario, mejorando la calidad de vida en su vivienda y manteniendo su permanencia en el entorno habitual durante el mayor tiempo posible, constituyendo la opción, por otra parte, preferida en su mayoría por los destinatarios por cuanto permite conservar algunos vínculos importantes para el desarrollo integral de la persona $^{18}$. Hacer esta realidad posible supone actuar en el plano de lo personal y en las labores domésticas (art. 23 LD) a desarrollar en el domicilio del beneficiario, quien podrá tener que contribuir económicamente "según el tipo y coste del servicio y su capacidad económica personal" (art. 33.1 de la LD). Indudablemente supuso un gran avance en la conquista de derechos sociales a la par que un enorme reto para las para Comunidades Autónomas y Corporaciones Locales que debían adaptar su entramado jurídico y sistemas de gestión marcados por una multiplicidad de modelos a la nueva realidad normativa.

En este punto, la cuestión nuclear radica en adaptar la coexistencia de dos servicios que presentando similares características en cuanto a su prestación mantienen una diferencia fundamental: mientras que el SAD amparado en la LD constituye un verdadero derecho subjetivo para cuantos alcanzan la condición de dependiente, el servicio dispensado hasta entonces por las Corporaciones Locales tenía un carácter más discrecional y variado dependiendo del baremo establecido al efecto por cada Entidad Local y de su reglamentación - y altamente ligado al factor presupuestario, situación que propiciaba algunas carencias como - apuntando las más importantes - su baja prescripción, su escasa vinculación, la evidente cobertura desigual entre las Comunidades Autónomas e incluso en los propios municipios de una misma entidad territorial, la falta de diferenciación entre las tareas y los cuidados personales, su estrecha relación con la capacidad económica del beneficiario, o, por no seguir, la escasa o nula coordinación con los sistemas de salud y una grave deficiencia en materia gestión ante la coexistencia, en los mismos territorios, de gestión pública, contratada, concertada y subvencionada.

En todo caso no cabe olvidar que la nueva norma estatal vino a aportar la necesaria universalidad y extensión de una prestación que necesitaba romper con la ligazón que suponía la limitación de su concesión a las rentas más bajas, procediendo su extensión a cuantos lo tuvieran prescrito su Programa Individual de Atención en el marco del Sistema para la Autonomía y Atención a la Dependencia como derecho que las Administraciones Públicas están llamadas a garantizar y hacer efectivo en un marco más homogéneo y con unos estándares de calidad en todo el territorio nacional.

Indudablemente, el SAD se ha convertido en uno de los servicios fundamentales asociados a la LD cuya configuración está marcada por una regulación anterior en el marco de los servicios sociales a nivel nacional y autonómico.

Abundando en el panorama esbozado, las Comunidades Autónomas en el ejercicio de su competencia y mediante su propia legislación en materia de servicios sociales, tienen la

${ }^{18}$ SANCHO CASTIELLO, M. Y DÍAZ MARTÍN, R.: "Atención a las personas mayores en su entorno: teleasistencia, ayuda a domicilio y centros de día”, Sociedad y Utopía. Revista de Ciencias Sociales, núm. 30, 2007, pág. 163. 
capacidad de otorgar más o menos peso a cada una de las dos modalidades en las que se presenta la prestación del SAD distinguiendo entre cuantas en sus normas ligan el servicio de manera preponderante a la LD y aquellas que apuestan por el mantenimiento en su territorio de un servicio vinculado al básico de las Corporaciones Locales con las desigualdades que ello supone — no cabe olvidar la mencionada modificación ofrecida en el art. 27 de la Ley 27/2013de 27 de diciembre, de Racionalización y Sostenibilidad de la Administración Local, cuando condiciona la efectividad de la delegación competencial a los Ayuntamientos al acompañamiento de medidas de financiación para hacer frente a las nuevas competencias adquiridas - ; por otro, las que al margen normativo estatal siguen ofreciendo un servicio ligado a connotaciones económicas y de auxilio social.

Procede así la prestación de un similar servicio bajo un diferente prisma que aporta una doble perspectiva o dimensión: por un lado, como prestación básica y necesaria de carácter comunitario, concedida por los servicios sociales locales en función de situaciones sociales determinadas; por otro, como prestación especializada, derivada del Sistema para la Autonomía y Atención a la Dependencia (SAAD) cuyos destinatarios han de ser calificados como dependientes según los criterios marcados en la normativa de dependencia. La necesidad de cohonestar ambos supuestos da lugar a consecuencias distintas en función del tipo de servicio al que accede en beneficiario ${ }^{19}$.

\section{Configuración de la prestación básica del Servicio de Ayuda a Domicilio en el marco de los servicios sociales}

La concepción de este tipo de SAD supone entenderlo como prestación básica cuyo reconocimiento corresponde a los servicios sociales de atención primaria y respecto del cual la competencia íntegra en materia de gestión pertenece a la Entidad Local (en el marco descrito por la Ley Reguladora de Bases del Régimen Local), modalidad que por regla general no reviste a la prestación del carácter de derecho subjetivo que si otorga la prestación amparada en la LD restando garantías en su concesión ${ }^{20}$.

En todo caso, y haciendo uso de sus competencias, dependerá de las normativas concretas de carácter autonómico el elevar a categoría de derecho subjetivo esta modalidad prestacional, como han hecho las pertinentes normas de Andalucía (arts. 1. c. y 42.2.k. de la Ley 9/2016, de 27 de diciembre, de servicios sociales de Andalucía), País Vasco (art. 3.1. del Decreto 185/2015, de 6 de octubre, de cartera de prestaciones y servicios del Sistema Vasco de Servicios Sociales) o Cataluña (art. 2.1 del Decreto 142/2010, de 11 de octubre, por el que sea aprueba la Cartera de servicios sociales).

En orden distinto no contemplan la situación descrita la normativa de Castilla y León (art. 1 del Decreto 269/1998, de 17 diciembre 1998, regula el SAD como prestación básica del sistema público de Servicios Sociales sin garantía adicional alguna en relación con el art. 5.1 y 2 del Decreto 58/2014, de 11 de diciembre, por el que se aprueba el Catálogo de

\footnotetext{
${ }^{19}$ REVUELTA ALONSO, M. ${ }^{\text {a }}$ L.: "La ayuda a domicilio como servicio de proximidad en el contexto social actual”, Humanismo y Trabajo Social, Vol. 15, 2015, págs. 112 y 119.

${ }^{20}$ PRADOS, C.: "Prevención y mantenimiento de la autonomía de los mayores: La ayuda a domicilio", Cuadernos de Trabajo Social, núm. 14 (Ejemplar dedicado a la vejez), 2001, págs. 291 a 300.
} 
servicios sociales de Castilla y León), Galicia (Decreto 61/2016, de 11 de febrero, por el que se define la Cartera de servicios sociales de inclusión con una estructura sensiblemente diferente al resto de Comunidades) o Madrid (Ley 11/2003, de 27 de marzo, de servicios sociales de la Comunidad de Madrid) que elude la referencia al servicio como prestación no disponiendo de cartera de servicios sociales básica más allá de la establecida en el marco de la LD y, en consecuencia, sólo considerando su esencialidad en los supuestos ligados al SAAD.

Por cuanto hace a los destinatarios del servicio, en la prescripción básica no existen límites de edad o criterios de dependencia para el acceso, dando cabida a cualquier individuo o entidad familiar limitadas en su autonomía personal de modo temporal o permanente, o en los cuales concurran determinadas situaciones que les impidan hacer frente a sus actividades más cotidianas — como rezan las reglamentaciones y ordenanzas municipales - , ampliando el campo de aplicación respecto al contemplado en la LD en dos sentidos: por un lado, contemplando la posibilidad de necesidades del servicio con carácter temporal, alejándose del concepto de dependencia de la norma nacional cuando define ésta como estado "de carácter permanente"; por otro, cuando incluye en su campo de aplicación a cuantos aun teniendo la condición de dependencia reconocida se encuentran en listas de espera y no disfrutan del servicio, extensión que presenta grandes ventajas cuando se trata de cubrir situaciones de incapacidad temporal producidas por hospitalización, urgencias o convalecencias. Sitúa además en su campo de aplicación a cuantas personas o unidades familiares con menores, desestructuradas o con carencia de hábitos funcionales necesitan de apoyo y servicio.

La intensidad de la prestación será una cuestión que también vendrá condicionada por las distintas normas y reglamentaciones autonómicas o municipales manteniendo en muchos casos un discurrir similar al establecido en el SAAD, mientras que en otros fijan intensidades propias.

\section{La prestación especializada del Servicio de Ayuda a Domicilio}

La prestación del SAD concebido como verdadero derecho subjetivo como es contemplado en el art. 1 LD y su inclusión en el Catálogo de servicios como prestación garantizada (art. 15 LD) cuya competencia y reconocimiento corresponderá a cada una de las Comunidades Autónomas — con independencia de su gestión por los entes locales correspondientes que a través de sus propias ordenanzas o reglamentos aquilatarán la extensión en la prestación del servicio-, supone un garante extraordinario en el acceso de este servicio cuando se cumplen los requisitos exigidos de acceso.

Partiendo así de los niveles básicos marcados por la LD, las Comunidades Autónomas deberán adecuar sus normas autonómicas con la declaración de la prestación como derecho subjetivo directamente exigible ante los tribunales ordinarios y ajustar el régimen de distribución competencial entre los sus entes locales de acuerdo con las carteras de servicios ofertados en cada caso por la Comunidad en cuestión siendo en todo caso la Administración autonómica la competente para el reconocimiento de la situación de dependencia, pese a que el servicio permanezca en el ámbito de la gestión de las entidades 
locales. En todo caso, la financiación se ajustará a lo establecido en los Convenios que se suscriban entre la Administración General del Estado y cada una de las administraciones de las Comunidades Autónomas en los cuales serán determinadas — conforme el art. 32.2. LD - las obligaciones asumidas por cada una de las partes para la financiación de los servicios y prestaciones del Sistema.

Los destinatarios del SAD de la dependencia se encuentran claramente tasados en cuantos se encuentran en declarada y reconocida situación de dependencia entendida como su propia ley reguladora establece y que viene definido por el estado de carácter permanente derivado de la edad, la enfermedad o la discapacidad, y ligadas a la falta o a la pérdida de autonomía física, mental, intelectual o sensorial, precisan de la atención de otra u otras personas o ayudas importantes para realizar actividades básicas de la vida diaria o, en el caso de las personas con discapacidad intelectual o enfermedad mental, de otros apoyos para su autonomía personal y cuyo plan de intervención personal así lo aconseje como la medida más idónea de intervención.

El servicio se destina a la atención de las necesidades de la vida diaria (atenciones personales y necesidades domésticas o del hogar), reforzando la idea de un apoyo integral prestado por profesionales a diferencia de la prestación básica de los servicios sociales que dirigían su atención de manera preponderante a las actividades del hogar que exigían, a su vez, escasa preparación.

Constituyendo este servicio uno de los escasos que miden su intensidad en horas de asistencia y cuidado, esta vendrá determinada con carácter general en el marco descrito en el Anexo II del Real Decreto 1051/2013, de 27 de diciembre, que establece el número de horas de atención mensuales en función del grado de dependencia determinado y el plan de intervención establecido y que oscila entre el máximo de 20 horas mensuales para el Grado I de Dependencia moderada (sin establecer mínimo alguno) hasta las 70 horas mensuales establecidas el Grado III de Gran Dependencia, actuando, en todo caso estos niveles como mínimos de protección a garantizar por las Administraciones locales y que las Comunidades Autónomas pueden mejorar ofreciendo un incremento en el número de horas del servicio con cargo a sus presupuestos.

El marco descrito es fruto, sin embargo, de algunas modificaciones importantes. Es reseñable como este servicio ha sufrido algunas estrangulaciones presupuestarias que han encontrado traducción en una pérdida de intensidad en el tiempo como muestran las normas regulatorias del mismo ${ }^{21}$; así, mientras que el Real Decreto 727/2007, de 8 de junio, sobre criterios para determinar la intensidad de los servicios y la cuantía de las prestaciones económicas de la LD establecía una intensidad de la prestación expresada en horas mensuales de atención según grados $-\mathrm{y}$ en ese momento también según niveles recogiendo en su anexo I un número que oscilaba entre 70 y 90 horas (gran dependencia, nivel 2), entre 55 horas y 70 (gran dependencia, nivel 2), entre 40 y 55 horas (dependencia

\footnotetext{
${ }^{21}$ MONSERRAT CODORNIU, J.: "Sostenibilidad del sistema de atención a la dependencia”, Papeles de Economía Española, núm. 161, 2019, págs. 164 y ss.
} 
severa, nivel 2), y entre 30 y 40 horas (dependencia moderada, nivel 2) - el Real DecretoLey 20/2012, de 13 de julio, de medidas para garantizar la estabilidad presupuestaria y de fomento de la competitividad, que procede a la rebaja de las horas de dedicación según grados, para todas las prestaciones de servicios del SAAD, estableciendo un servicio de entre 46 y 70 horas para la gran dependencia (20 horas mensuales menos en cuanto al máximo nivel y solo 15 más respecto del nivel más bajo de la gran dependencia); entre 21 y 45 horas mensuales para la dependencia severa (diez menos en cuanto al máximo nivel y también nueve horas menos si se compara con el nivel más bajo); y, finalmente, asignado a la dependencia moderada un máximo 20 horas mensuales de atención. Esta rebaja generalizada persigue sin duda una finalidad de ahorro de costes pese al deterioro sensible que ello supone en la prestación del SAD. Esta situación es aún más grave por cuanto la merma de horas de prestación no solo afectará a aquellas prestaciones cuyo reconocimiento se haya producido a partir del 1 de agosto de 2012 (en tanto la efectividad queda diferida a partir del día primero del mes siguiente a la entrada en vigor) sino también a las ya vigentes, en relación con las cuales la disposición transitoria 12. ${ }^{a}$ del Real Decreto-Ley 20/2012 señala que las administraciones competentes fundamentalmente las CCAA — podrán realizar las adaptaciones necesarias para adecuar sus reglas a las intensidades descritas, lo que significa, en suma que tiene la posibilidad de reducir hacia estos mínimos las ya concedidas.

\section{El declive de la financiación del SAD: una muerte anunciada de los Planes Concertados de Prestaciones Básicas de Servicios Sociales y otras formas de sostenibilidad}

Las crisis económicas no han dejado indiferente a un servicio cuya calidad se encuentra altamente ligada a una adecuada financiación capaz de hacer frente a las demandas existentes a través de profesionales cualificados. Para proceder al análisis de la situación financiera es preciso partir del incremento importante de los potenciales usuarios de un servicio que durante mucho tiempo atendía mayoritariamente — en su vertiente básicanecesidades de carácter familiar relacionada con el cuidado de menores, y que crece de forma ostensible hacia la preponderancia del cuidado de la población de mayor edad.

Los sucesivos recortes en los presupuestos producidos en el SAD, han llevado a las Corporaciones Locales a establecer unos regímenes de copagos muy elevados ante una población beneficiaria que también ha sufrido una paulatina - pero constantedisminución de recursos económicos.

Para entender la situación de hoy con la perspectiva adecuada hay que partir de la aprobación de las primeras leyes autonómicas de servicios sociales y de la Ley 7/1985 reguladora de las Bases del Régimen Local, que atribuía a los Municipios las competencias en materia de prestación de los servicios sociales y de promoción y reinserción social. Ante esta situación y la urgente necesidad de articular prestaciones y servicios básicos para todo el territorio español surge en 1988 un modelo de cooperación económica y técnica que con la denominación de Plan Concertado de Prestaciones 
Básicas de Servicios Sociales (PCPB) destinaba sus esfuerzos a la implantación de una red básica de atención de servicios sociales en los municipios ${ }^{22}$.

Este instrumento trataba de garantizar con cierta homogeneidad unos servicios sociales básicos de calidad entre los que figura la ayuda a domicilio, al abrigo jurídico proporcionado por la CE —en los arts. 41, 139, 148.1.20 y 149.1.1—, por la Ley Reguladora de Bases del Régimen Local —en su redacción de 1988-, y el correspondiente convenio administrativo celebrado entre las tres Administraciones Públicas implicadas — estatal, autonómica y local—, en aras de garantizar unos servicios sociales que ofrecieran bienestar, públicos y de carácter gratuito. En concreto, el objetivo en cuestión respecto al SAD consistía en proporcionar a los individuos y/o familias ayuda en su domicilio cuando no son capaces de afrontar la realización de sus actividades habituales más básicas o padecen situaciones de conflicto de carácter social, psicológico o familiar ${ }^{23}$.

El ambicioso objetivo del PCPB queda, sin embargo, mermado por cuestiones de carácter económico si bien continúa siendo el principal instrumento de cooperación técnica y financiera de alcance estatal en esta materia a pesar del acusado descenso de su peso en los presupuestos globales de servicios sociales en el ámbito local, pero permite proceder al análisis de la situación en el panorama nacional o por Comunidades Autónomas o Entidades Locales. El Convenio/Contrato administrativo recoge la responsabilidad de la gestión de los proyectos por las Entidades Locales y la necesidad de que la aportación de las Comunidades y Ciudades Autónomas sean iguales o superiores a las de la Administración del Estado. No cabe olvidar que, en el sistema competencial diseñado en las diversas normativas autonómicas de servicios sociales, constituye una función privativa de las Comunidades la planificación de tales servicios, siendo las propias autonomías las que mediante convenios o subvenciones establezcan las cuantías a destinar con cada Corporación o Ente Local, responsable, a su vez, de proceder a la financiación de los servicios sociales básicos en su ámbito territorial.

Los datos ofrecidos para el año 2016 por la Administración General del Estado, ponen de manifiesto que las Comunidades y Ciudades Autónomas son quienes contribuyen con mayor porcentaje en la financiación del PCPB $(51,66 \%)$ seguidas de cerca por las Administraciones Locales (46,55\%), constituyendo la aportación ministerial $(1,7 \%)$ una escasa cifra respecto del total.

\footnotetext{
${ }^{22}$ GUTIÉRREZ RESA, A.: "El Plan Concertado de Prestaciones Básicas de Servicios Sociales en España (Once años de Plan Concertado)", Revista Española de Investigaciones Sociológicas, núm. 93, 2001, pág. 106 y ss.

${ }^{23}$ BREZMES NIETO, Ma. J.: "El Sistema Público de Servicios Sociales 19 años después. Del plan concertado para las prestaciones básicas a la Ley de la Autonomía Personal", en AA.VV. (HIDALGO LAVIÉ, A. Coord): Trabajo social en el ámbito de la Ley de Promoción de la Autonomía Personal y atención a las personas en situación de dependencia: la profesión, la ley y los servicios sociales a debate, A Coruña (Netbiblo), 2011, págs. 99-112.
} 
De la distribución por Comunidad Autónoma que se refleja en la siguiente tabla, es posible apreciar ciertas desviaciones respecto del promedio global entre las diferentes administraciones, manteniendo un perfil similar al de años anteriores.

\begin{tabular}{|c|c|c|c|c|c|c|c|}
\hline ADMINISTRACIÓN & \multicolumn{2}{|c|}{ MINISTERIO } & \multicolumn{2}{|l|}{ CCAA } & \multicolumn{2}{|c|}{ CORPORAC. LOCALES } & TOTAL \\
\hline CCAA & APORTACIÓN & $\%$ & APORTACIÓN & $\%$ & APORTACIÓN & $\%$ & APORTACIONES \\
\hline ANDALUCÍA & $5.358 .655,57 \mid$ & 0,88 & $389.814 .148,88$ & 64,10 & $212.913 .668,81$ & 35,01 & $608.170 .435,97$ \\
\hline ARAGÓN & $942.955,74$ & 7,32 & $6.529 .932,00$ & 50,67 & $5.414 .619,80$ & 42,01 & $12.887 .507,54$ \\
\hline CANARIAS & $1.190 .600,69$ & 1,77 & $12.020 .570,01$ & 17,90 & $53.928 .066,49$ & 80,32 & $67.139 .237,19$ \\
\hline CANTABRIA & $420.724,27$ & 1,57 & $14.764 .669,00$ & 54,99 & $11.664 .411,60$ & 43,44 & $26.849 .804,87$ \\
\hline CASTILLA-LA MANCHA & $1.434 .435,71$ & 9,12 & $8.361 .162,61$ & 53,16 & $5.934 .097,98$ & 37,73 & $15.729 .696,30$ \\
\hline CATALUÑA & $3.870 .608,82$ & 1,62 & $82.097 .924,34$ & 34,46 & $152.283 .692,86$ & 63,92 & $238.252 .226,02$ \\
\hline CASTILLA Y LEÓN & $2.076 .951,87$ & 1,45 & $89.046 .929,62$ & 62,00 & $52.506 .827,01$ & 36,56 & $143.630 .708,50$ \\
\hline COMUNIDAD DE MADRID & $3.128 .490,40$ & 2,85 & $93.690 .493,09$ & 85,29 & $13.032 .852,12$ & 11,86 & $109.851 .835,61$ \\
\hline CIUDAD DE CEUTA & $236.068,65$ & 48,99 & $245.822,08$ & 51,01 & 0,00 & 0,00 & $481.890,73$ \\
\hline CIUDAD DE MELILLA & $236.068,65$ & 1,96 & $11.799 .299,53$ & 98,04 & 0,00 & 0,00 & $12.035 .368,18$ \\
\hline COMUNIDAD VALENCIANA & $2.708 .582,55$ & 2,98 & $22.053 .271,66$ & 24,27 & $66.114 .497,85$ & 72,75 & $90.876 .352,06$ \\
\hline EXTREMADURA & $941.050,78$ & 49,41 & $944.565,14$ & 49,59 & $19.046,63$ & 1,00 & $1.904 .662,55$ \\
\hline GALICIA & $2.276 .428,51$ & 1,24 & $66.134 .800,60$ & 36,04 & $113.714 .273,66$ & 61,98 & $183.484 .025,99$ \\
\hline ISLAS BALEARES & $525.497,13$ & 2,40 & $3.007 .119,60$ & 13,76 & $18.319 .860,75$ & 83,83 & $21.852 .477,48$ \\
\hline LA RIOJA & $408.205,95$ & 32,89 & $408.205,95$ & 32,89 & $424.570,90$ & 34,21 & $1.240 .982,80$ \\
\hline PRINCIPADO DE ASTURIAS & $853.966,85$ & 1,57 & $25.946 .033,15$ & 47,62 & $27.682 .458,79$ & 50,81 & $54.482 .458,79$ \\
\hline REGIÓN DE MURCIA & $804.437,86$ & 3,14 & $7.235 .338,48$ & 28,22 & $17.595 .737,35$ & 68,64 & $25.635 .513,69$ \\
\hline SUMA & $27.413 .730,00$ & 1,70 & $834.100 .285,74$ & 51,66 & $751.548 .682,60$ & 46,55 & $1.614 .505 .184,27$ \\
\hline
\end{tabular}

Tabla 1. Elaboración Propia

Fuente: Ministerio de Sanidad, Consumo y Bienestar Social. 2016.

En la gran mayoría de los casos, la aportación del Ministerio de Sanidad, Consumo y Bienestar Social es muy escasa. Sin embargo, destacan, con más de un $20 \%$ de participación y marcando una clara distancia con las demás regiones la Ciudad Autónoma de Ceuta $(48,99 \%)$ y las Comunidades de Extremadura (49,41\%), La Rioja (32,89\%).

Por cuanto hace a la aportación de las Comunidades Autónomas, superan la barrera del 50\% de la aportación las Ciudades Autónomas de Ceuta y Melilla, Andalucía, Aragón, Cantabria, Castilla La Mancha, Castilla y León y la Comunidad de Madrid.

En el supuesto de la aportación de las Corporaciones Locales, es en los archipiélagos de las Islas Baleares e Islas Canarias y en la Comunidad Valenciana donde el porcentaje sobre la financiación total es superior al $70 \%$, siendo llamativa en sentido contrario la situación en este caso de Ceuta y Melilla o de Extremadura. 
Por otra parte, la mayoría de CCAA disponen de catálogos y carteras de servicios sociales que concretan, además de los aspectos básicos como la naturaleza de las prestaciones, el tipo de prestación (técnicas, económicas y tecnológicas) y la forma que adopta la financiación (gratuitas o de copago). Algunas permiten a los Entes Locales aprobar sus propios catálogos de servicios sociales que complementen las prestaciones de servicios sociales de ámbito general, cuyo ámbito de aplicación será el territorio del respectivo ente local y cuya financiación correrá a su exclusivo cargo. En otros casos, se reserva esta competencia a la Comarca o a Municipios con más de veinte mil habitantes que constituyan área básica de servicios sociales.

En todo caso, y volviendo a la cuestión nuclear de este trabajo centrada en la dualidad del servicio, este extremo también tiene reflejo en la financiación, dependiendo de la forma o la modalidad de acceso a la prestación.

El sistema de financiación de los servicios de la dependencia establece una doble vía mediante la cual se procede al sostenimiento del gasto: por un lado, la que corresponde a las Administraciones Públicas competentes -Administración General de Estado mediante los créditos que anualmente se fijan en los Presupuestos Generales del Estado y los Presupuestos de cada Comunidad Autónoma-; por otro, la aportación de los beneficiarios del sistema en el coste de las prestaciones, siempre en función de su capacidad económica personal y sin que en ningún caso sea posible quedar fuera de la cobertura del sistema por ausencia de recursos económicos ${ }^{24}$.

La protección configurada en la norma se articulaba en su origen en tres niveles de los cuales la financiación del mínimo correspondía íntegramente la Administración General del Estado, un segundo nivel sostenido mediante aportaciones acordadas entre la Administración General del Estado y las Comunidades Autónomas —en el cual la aportación de las Comunidades Autónomas deberá ser al menos igual a la de la Administración General del Estado- y un tercer nivel adicional que cada Comunidad Autónoma quisiera establecer y cuya financiación correría a cargo de la misma. Sin embargo, el pretendido objetivo de dar satisfacción a la cuestión de la dependencia con una norma ad hoc, ha sufrido sustanciales alteraciones debido a los recortes presupuestarios - de los que, aunque no el único, el más importante fue el llevado a cabo por el Real Decreto-Ley 20/2012, de 13 de julio, de medidas para garantizar la estabilidad presupuestaria y de fomento de la competitividad - que han encontrado manifestación en forma de trabas administrativas para adquirir la condición de dependiente o la disminución en las intensidades del servicio, de los que uno de los principales perjudicados fue, precisamente, la ayuda a domicilio ${ }^{25}$. Al panorama expuesto cabe añadir un cúmulo de sucesivas Leyes de Presupuestos Generales del Estado que desde 2012 suspendieron los convenios referentes al nivel acordado en los conciertos de financiación

${ }^{24}$ CONDE MARÍN, E.: "La financiación de la dependencia: la financiación pública de la dependencia", en AA.VV. (MOLERO GARCÍA, Ma . L., Coord.): Retos para una implantación efectiva del sistema para la autonomía y atención a la dependencia, Madrid (Cinca), 2012, págs. 193-212.

${ }^{25}$ RAMÍREZ NAVARRO, J.M.: "La demolició controlada del Sistema d'Atenció a la Dependència,

Revista de Treball Social, núm. 200, 2013, pág. 87. 
con las Comunidades Autónomas, por lo que los niveles de protección del sistema se han reducido a dos.

En este sentido, para aquellos que ostentan una situación reconocida de dependencia y en su Programa Individual de Actuación (PIA) contienen la prescripción del SAD, el servicio se financia con las aportaciones de la Comunidad Autónoma correspondiente, de la Administración General del Estado, de las Corporaciones Locales y la aportación de la persona destinataria del servicio. A sensu contrario, en el supuesto de acceder a la prestación básica del servicio, el usuario queda extra muros de la aplicación de la LD y la financiación corresponderá a la llevada a cabo mediante las aportaciones de las CC.AA y las Corporaciones Locales, y posibles - y escasas - aportaciones del Estado a través del PCPB, además de la llevada a cabo a cargo de la persona o unidad de convivencia destinataria del servicio (copago).

Todo lo expuesto vendría a justificar uno de los grandes males de los que adolece el SAD y que no es otro que su baja prescripción, situación altamente relacionada con el coste del servicio y que encuentra traducción en una insuficiencia mostrada en muchos casos sobre todo en cuanto a la intensidad de la atención profesional domiciliaria del SAD en casos de gran dependencia o dependencia severa-, no tanto por la propia concepción del servicio sino por sus limitaciones en la práctica, y que ha llevado a muchos países del entorno de la UE - entre ellos el nuestro - a la introducción de algunas variantes asociadas a este servicio capaces de cubrir necesidades concretas consiguiendo así una mayor eficiencia de los recursos utilizados y eficacia en la prestación de servicios concretos.

En el contexto descrito, aparecen otros servicios - que algunas Entidades Locales ya venían prestando - que vienen a intentar paliar estas deficiencias en la ausencia de autorización de servicios mediante otros programas de colaboran en la atención del necesitado y/o dependiente proporcionando soluciones concretas a problemas de carácter puntual o sostenidos en el tiempo que precisan de atención por los servicios sociales. Además del conocido y altamente solicitado servicio de la Teleasistencia, muy cercano en tanto que ofrece apoyo y ayuda personalizada las 24 horas del día mediante el uso del teléfono y equipos informáticos específicos, permitiendo a sus beneficiarios estar en contacto permanente con un Centro de Atención especializado capaz de prestarle asistencia directa y personal al usuario y compatible con la prestación del SAD dependiente, existen otras modalidades de ayuda que, si bien no cubren ni suplen la totalidad del servicio domiciliario, alivian las tareas a las que el beneficiario o sus cuidadores han de enfrentarse. Aquí encuentran cabida servicios como el de comida a domicilio o las soluciones dirigidas a conseguir el respiro familiar del cuidador informal.

\section{El servicio de comida a domicilio}

De entre los varios existentes, este servicio adquiere una relevancia fundamental en tanto está destinado a la provisión de una necesidad básica como es la alimentación del beneficiario. 
Mantiene - como el SAD — la dualidad en la forma de prestación: por un lado, la que corresponde a su forma básica; por otro, aquella asociada a la dependencia.

En el primer supuesto, su prestación básica como un servicio complementario del SAD correspondería a los servicios sociales de atención primaria, no constituyendo una prestación garantizada y cuyas condiciones de acceso, mantenimiento y requisitos de los destinatarios serán objeto de regulación en las Ordenanzas Municipales de cuantas Entidades Locales deseen ofrecerlo ya que no se presta por parte de todos los Ayuntamientos. Como servicio de apoyo a otros existentes, su finalidad consiste en conseguir mantener la permanencia en el entorno habitual del beneficiario y, de forma específica, asegurar una alimentación adecuada a través de la elaboración de dietas equilibradas y posterior distribución en el domicilio de los usuarios.

En el segundo $-\mathrm{y}$ con la misma finalidad - aparece la prestación del servicio que algunas Comunidades Autónomas ofrecen, en este supuesto como servicio garantizado, ofertado desde el SAAD y destinado a personas que, valoradas en algunos de los Grados de Dependencia descritos por la norma, generan el derecho a la protección del sistema de la dependencia.

En ambos casos, aparece como un rasgo común en cualquiera de las modalidades es que el servicio implica una participación económica del usuario en el coste, que se determinará según ordenanza municipal.

El tratamiento —como ocurre en otras prestaciones básicas de asistencia social primaria - difiere en función de la normativa de servicios sociales de cada Comunidad Autónoma y, en última instancia de la Corporación Local en la cual sea prestado. Basten algunos ejemplos para ilustrar esta situación.

La Comunidad cántabra presenta las dos vertientes del servicio: por un lado, aquel extra muros de la dependencia y no garantizado prestado desde los Servicios Sociales de Atención Primaria; por otro, el complementario del SAD que elabora dietas equilibradas y las distribuye posteriormente al domicilio de los usuarios, cuyos beneficiarios son personas en situación de dependencia en cuyo PIA tengan reconocido esta prestación, otorgándola así carácter de garantizada. Así, en su catálogo de servicios incluye la posibilidad de que parte de la atención doméstica pueda ser realizada mediante servicios de comidas o lavandería a domicilio ${ }^{26}$. Este servicio muestra plena compatibilidad con el SAD y la Teleasistencia obtenidos por la vía de la dependencia, siendo incompatible con el disfrute del mismo servicio cuando es ofertado por los Servicios Sociales de Atención Primaria de los Ayuntamientos y con las prestaciones económicas del SAAD.

En el supuesto de Extremadura, oferta un Servicio de elaboración y entrega regular de comidas en domicilio para la alimentación diaria de personas dependientes en la realización de las actividades básicas de la vida diaria destinado a cubrir tres aspectos

\footnotetext{
${ }^{26}$ Orden EMP/48/2009, de 24 de abril, por la que se desarrolla el catálogo de servicios del sistema para la autonomía personal y la atención a la dependencia y se regula la aportación económica de las personas usuarias en la Comunidad Autónoma de Cantabria.
} 
fundamentales: dar servicio de comidas entregadas a domicilio, implicar una alimentación diaria y estar dirigido a personas en situación de dependencia. Constituye un servicio sujeto a la normativa de servicios sociales de la Comunidad Autónoma de Extremadura que requiere la previa autorización del Servicio Extremeño de promoción de la Autonomía y Atención a la Dependencia y la autorización sanitaria correspondiente. Muestra de su marcada proximidad es la implicación exigida a la entidad prestadora de las comidas con los usuarios, en tanto debe supervisar sus necesidades de ayuda y adquirir preocupación por su capacidad funcional en orden a dar cumplimiento al fin de poder mantenerse en su domicilio. El servicio es prestado en estrecha ligazón con la atención de una necesidad personal básica diaria, y, por lo tanto, dirigido a aquellos en situación de dependencia. En tanto los servicios de comidas a domicilio no son servicios acreditados del sistema de atención a la dependencia no están contemplados como tales en el Catálogo de Servicios de Atención a la Dependencia y, por lo tanto, no pueden pagarse con prestaciones o ayudas económicas públicas derivadas de la Ley de Atención a la Dependencia. No obstante, son servicios que podrían estar vinculados a un servicio de ayuda a domicilio acreditado, y podría estar subvencionado, siempre que se contrate dentro de un servicio integral de ayuda a domicilio. Como servicio ofertado por la propia Comunidad Autónoma, no es incompatible con otros servicios de comidas a domicilio u otros destinatarios; en tal sentido estará destinado a cuantos presentan incapacidad funcional o gran dificultad, física y/o sensorial, para elaborarse diariamente su propia comida, y que no disponen de suficiente apoyo familiar que se la proporcione; aquellos que, de manera temporal se encuentren en la situación anteriormente descrita; los que, a causa de un deterioro cognitivo o una discapacidad psíquica, se encuentren en situación de riesgo o peligro para la elaboración de comidas, por incapacidad para usar cocinas y realizar compras, y no dispongan de suficiente apoyo familiar que se las proporcione; o personas en situación de exclusión social que presenten malnutrición o alto riesgo de malnutrición por su aislamiento o por trastornos psíquicos y emocionales que les impiden llevar una alimentación adecuada sin ayuda social.

El caso valenciano precisa del previo informe social y médico favorable para acceder a esta prestación concreta. Ofrece el servicio para personas situadas en ciertos límites de edad a través del Programa Menjar a casa, que exige reunir unos requisitos básicos edad de 65 años o más; 60 años en situación de dependencia y para personas con discapacidad en situación de dependencia, mayores de 18 años, que convivan con la persona mayor de 65 años beneficiaria del programa-, disponer de autonomía para la preparación e ingesta de los alimentos servidos, o bien aportar compromiso de familiares o de la entidad local que se responsabilicen de dicha tarea, estar empadronado en alguno de los ayuntamientos que participan en el programa y cuyo ayuntamiento haya formalizado el correspondiente convenio de colaboración con la administración autonómica.

Por último - de entre los muchos existentes - reseñar el programa que con la denominación Xantar na Casa, Galicia gestiona a través del Consorcio Gallego de Servicios de Igualdad y Bienestar y aquellos ayuntamientos que estén consorciados. Los 
potenciales destinatarios son personas mayores de 60 años con limitaciones de su autonomía personal y sin redes de apoyo que puedan suplir esta situación; personas dependientes, que carezcan de apoyo familiar, y que requieran de ayuda para la preparación de los alimentos; y, personas menores de 60 años, en situación de exclusión social o en riesgo de estarlo.

\section{El Bono Respiro y programas afines}

En un sistema público de bienestar incapaz de proporcionar cuidados o apoyos domiciliarios preventivos desde las competentes entidades de servicios sociales que, sin embargo, incurren en elevados gastos hospitalarios, farmacéuticos o tecnológicos, en gran parte causados por la ausencia de una intervención social más temprana ${ }^{27}$, ofrecen especial interés las fórmulas destinadas a la prevención y la permanencia el mayor tiempo posible en los hogares de las personas con dependencia, pero que necesariamente han de ser completados con servicios y apoyos adecuados, mediante un tipo de programa que a la par que favorezca la permanencia en los hogares de las personas con dependencia brinde el apoyo necesario a las personas cuidadoras primarias ${ }^{28}$.

Los cuidadores familiares que prestan su atención a un familiar dependiente que precisa de ayuda en el desarrollo de sus actividades de la vida diaria asumen un elevado volumen de tareas diarias que pueden ocasionar cierta carga física y emocional. De hecho, el apoyo informal - fundamentalmente el procedente de la familia - es una de las fuentes de ayuda más importantes que, prolongada en el tiempo, es capaz de producir efectos negativos no sólo sobre el cuidador sino sobre la calidad misma de los cuidados que provee $^{29}$.

En clara sintonía con esta realidad, la LD recoge en su art. 25.3 la posibilidad de la prestación del servicio de atención residencial con carácter temporal como fórmula de apoyo familiar, con el objetivo de cubrir estancias temporales de convalecencia o durante periodos vacacionales, fines de semana y enfermedades o periodos de descanso de los cuidadores no profesionales. En este sentido, el beneficio del servicio repercute en persona distinta del usuario principal en tanto éste disfruta de atenciones temporales en un centro especializado y se facilita el descanso de los cuidadores mediante un período de desconexión.

El servicio presenta, indudablemente, unos beneficios tanto para el cuidador como para la persona cuidada: respecto al primero, resuelve situaciones de necesidad de disponer de tiempo de descanso, ocio y tiempo libre y atender las necesidades de su vida personal y laboral; por cuanto afecta al cuidado, recibe atención profesional e individualizada con

${ }^{27}$ FANTOVA AZCOAGA, F.: “Crisis de los cuidados y servicios sociales”, Zerbitzuan, núm. 60, 2015, pág. 57.

${ }^{28}$ YACEN ROJAS, K.: "Programas de respiro en el domicilio y acompañamiento a las personas cuidadoras primarias, una estrategia clave para humanizar la relación de cuidados en el ámbito familiar: el caso de Alkar Zaintzen", Zerbitzuan, núm. 73, 2020, pág. 68.

${ }^{29}$ MARTÍNEZ, M.F.; VILLALBA, C., y GARCÍA, M.: "Programas de respiro para cuidadores familiares", Intervención Psicosocial, Vol. 10, núm. 1, 2001, pág. 11. 
acceso en igualdad de condiciones que el resto de los residentes habituales a terapias y/o tratamientos difíciles de aportar en el ámbito del cuidado familiar.

Como servicio público, su finalidad es conseguir la máxima estabilidad familiar posible, permitiendo que las personas en situación de dependencia puedan continuar viviendo en su hogar y evitar que, durante los períodos en los que el cuidador no pueda hacerse cargo, sufran un retroceso o pérdida de calidad en su atención y en los cuidados.

Son muchos los Catálogos de Prestaciones y Servicios autonómicos que recogen la posibilidad de estancias temporales como herramienta de apoyo y descanso familiar. En todo caso, entre los requisitos generales exigidos se encuentran ser mayor de 16 años con reconocimiento de discapacidad o de dependencia (Grado II o III) y aquellos que, no pudiendo acreditar los requisitos anteriores, requieran da atención de un cuidador; residencia en la comunidad o municipio donde se solicita; no padecer enfermedad que requiera atención imprescindible en un centro hospitalario ni que se encuentren en estado terminal; no padecer enfermedad infecto-contagiosa activa, trastornos mentales o conductuales graves y no compensados que puedan alterar la convivencia; no haber sido sancionado con expulsión definitiva de un centro residencial; y, compromiso de llevar a cabo la solicitud y el pago del precio estipulado en las condiciones indicadas.

Además de los supra mencionados de carácter general, la mayoría de las empresas privadas y algunas entidades sociales, disponen de plazas para estancias temporales durante todo el año con condiciones y requisitos propios.

Con estas mimbres y bajo diferentes denominaciones, aparecen programas financiados por las Comunidades Autónomas que, mediante un sistema de Subvenciones o ayudas, se dirigen a sufragar los gastos generados por las estancias temporales de personas mayores y/o dependientes en centros residenciales durante determinados periodos al año. Se trata de una prestación que no figura en los catálogos de servicios y que no tiene el carácter de garantizada.

De entre los diferentes programas, por su importancia e intensidad destaca el propuesto por la Generalitat Valenciana, que presenta uno de los más completos en orden a cubrir diferentes variantes en las necesidades de apoyo que necesita el cuidador principal a través del establecimiento de tres modalidades de intensidad del Bono Respiro: uno de carácter mensual - Bono Verde que permite estancia durante un mes en una residencia de tercera edad, cuando por necesidades sanitarias o sociales la persona mayor necesite la atención integral en un centro especializado-; otro de uso diario - Bono Azul consistente en 20 bonos diarios para la atención en residencias de tercera edad-; y, el destinado a cubrir los fines de semana - Bono Blanco, que ofrece 12 bonos para su disfrute en una residencia de tercera edad, en los fines de semana que el interesado elija, de acuerdo con el centro en el que vaya a ser atendido-; en todos los supuestos con las cuantías que sean fijadas cada año en las convocatorias correspondientes ${ }^{30}$.

\footnotetext{
${ }^{30}$ Art. 3, Orden 7/2016, de 7 de abril, de la Vicepresidencia y Conselleria de Igualdad y Políticas Inclusivas, por la que se establecen las bases reguladoras de la concesión de subvenciones relativas al programa Bono
} 
En el supuesto de Castilla y León los destinatarios son únicamente personas con cierto grado de dependencia. La Ayuda económica para el descanso del cuidador que puede conceder la Administración autonómica está dirigida a colaborar en el gasto que genera la estancia de una persona dependiente en un centro residencial durante un periodo de un mes al año. Para tener la condición de beneficiario se exige un grado III de dependencia, el previo reconocimiento de la prestación económica de cuidados en el entorno familiar, no estén sometidos a un sistema de rotación de cuidadores y tengan incluido en su PIA el servicio de atención residencial. La ayuda consiste en una cuantía económica equivalente al importe mensual de la prestación económica vinculada.

Por otro lado, también existe la posibilidad de acceder a programas de respiro en domicilio en los cuales se atiende por periodos de tiempo más largos que el SAD y se incorpora la atención a la persona cuidadora como parte fundamental en el cuidado. Aparece, así, un servicio con una doble funcionalidad que trata de conseguir paralelamente objetivos de mejora en la calidad de vida de la persona cuidadora y mantenimiento de la autonomía personal de la persona con dependencia, permitiendo el descanso de unas horas semanales a la primera, pero priorizando la permanencia de la segunda en su entorno y/o domicilio habitual.

\section{A modo de conclusión}

Procediendo al balance de la situación descrita, la realidad muestra que buena parte de las Comunidades Autónomas no han creado ningún modelo nuevo de ayuda o asistencia a domicilio, sino que han procedido a una remodelación de carácter formal de la organización y gestión, creando gran confusión entre la ayuda a domicilio como prestación básica de los Servicios Sociales y aquella otra que encuentra abrigo en el SAAD. La situación se enmaraña de manera considerable por cuanto existen grandes trabas administrativas a la hora de cohonestar la nueva prestación en unos servicios de larga tradición ya constituidos lo que supone su escasa aplicación en algunas comunidades. Lo deseable sería, por tanto, reforzar un mecanismo único de entrada a los servicios de ayuda a domicilio que, con soporte en la red básica de Servicios Sociales, proceda a engarzar los dos mecanismos de protección en aras de conseguir un mejor servicio y trasladar al potencial usuario del servicio la información necesaria de manera más clara y sencilla.

Lo cierto es que no es posible constatar la existencia de grandes diferencias entre el SAD básico o el ligado a la dependencia más allá de la naturaleza jurídica de la prestación establecida en su regulación básica o especializada - o el marco de extensión de los beneficiarios por cuanto el servicio final va a incluir actuaciones de atención personal y doméstica de igual modo como elemento nuclear de ambas modalidades, potenciando, en todo caso, las primeras como elemento modulador de un servicio dirigido a la integración

Respiro y subvenciones para financiar estancias en centros de día para personas dependientes y en residencias de tercera edad. 
y normalización del usuario en su entorno. Si existen, sin embargo, dos aspectos que suponen un problema al respecto: por un lado, la disparidad en la gestión de la demanda, especialmente en los contrastes existentes entre CCAA respecto de los tiempos de resolución, manejo de la información estadística, financiación, diferencias entre personas con resolución favorable para recibir prestaciones respecto de la cantidad de dependientes con PIA asignado y disfrute efectivo de prestaciones $^{31}$; por otro, las dificultades que supone un desigual desarrollo en materia de prestaciones y servicios entre CCAA, así como la falta de inversión en la calidad del modelo de atención ${ }^{32}$.

Sin embargo, cabe resaltar otro extremo común que trasciende la dualidad entre las dos modalidades del SAD y no es otro que el espíritu que marca el servicio respecto a la permanencia en el propio domicilio del beneficiario siempre que sea posible como lugar preferente para el ejercicio de la prestación para lo cual es preciso el mantenimiento de ciertas condiciones de habitabilidad o movilidad adecuadas en el mismo, optando en ambos casos por servicios o prestaciones diferentes cuando este aspecto fundamental no se cumple.

Con todo y con independencia del variopinto y extenso marco de desarrollo de la prestación, las diferentes leyes autonómicas mantienen similares criterios en algunos aspectos importantes que es preciso destacar: a la hora de regular este servicio mantienen en su oferta la dicotomía funcional de los servicios sociales entre un nivel primario o general — entre los que se encuentra el SAD — y otro secundario o especializado — si bien con diferentes denominaciones y contenidos - conservando en ambos casos la competencia en materia de gestión y prestación de servicio las Entidades Locales, dado su remarcando carácter de servicio de proximidad.

En concreto, también el SAD presenta grandes semejanzas en toda la normativa autonómica sustentada en la doble categorización de prestaciones domésticas y de atención personal, cobrando las segundas un mayor peso y calidad a partir de la implantación del SAAD. De hecho, uno de los mayores avances en el ámbito autonómico viene dado cuando su normativa desciende a una clasificación más detallada de lo que cabe entender por cuidados personales, incrementado la protección desde las meras tareas de cuidado personal, a las de carácter psicosocial, educativo y técnico pese al desigual desarrollo entre unas comunidades y otras.

En otro orden, se mantiene cierta homogeneidad en cuanto a las formas de financiación - por iniciativa de la Administración General del Estado y con la colaboración y financiación conjunta entre ésta, las respectivas Comunidades Autónomas y las Corporaciones Locales, a la par que cuentan con sistemas de participación o copago de

${ }^{31}$ HUETE GARCíA, A., CHAVERRI CARBAJAL, A. y MORALES ROMO, N.: "El sistema para la autonomía y atención a la dependencia en España (SAAD). Memoria de debilidades desde su implantación”, Prisma Social: Revista de Investigación Social, núm. 32, 2021, pág. 29.

${ }^{32}$ CERVERA, M., HERCE, J, LÓPEZ-CASASNOVAS, J, RODRÍGUEZ-CABRERO, G, y SOSVILLA, S.: Informe final del grupo de expertos para la evaluación del desarrollo y efectiva aplicación de la Ley 39/2006, 14 de diciembre, de Promoción de la Autonomía Personal y Atención a las Personas en Situación de Dependencia, 2009, IMSERSO. 
los usuarios - y con independencia de que la gestión sea pública o privada, se mantiene la responsabilidad pública sobre el sistema como garante principal. En este sentido, la normativa autonómica suele guardar grandes similitudes respecto a determinadas funciones municipales con respecto al $\mathrm{SAD}$, como servicio de responsabilidad pública pudiendo utilizar cualquier fórmula de gestión indirecta o colaboración de las previstas en el ordenamiento jurídico, a través de entidades de derecho público o privadas de carácter social o mercantil- y el carácter de competencia propia le confiere autonomía para su ejercicio, especialmente en los aspectos organizativos.

Sin embargo, es posible apreciar algunas variaciones importantes en el contenido de la ayuda y en la intensidad del servicio en función de la Comunidad Autónoma que la dispensa que, respetando - en todo caso - los campos mínimos que la LD exige cuando el sistema discurre por la vía de la declaración de dependiente, elude sin embargo detallar cuando se refiere en sentido amplio a la prestación de servicios relacionados con la atención personal en la realización de las actividades de la vida diaria y los relacionados con la atención de las necesidades domésticas o del hogar - limpieza, lavado, cocina u otros - dejando un claro margen de actuación y concreción del servicio a las autonomías y, por ende, a las Corporaciones Locales, en la oferta y de ejecución de la prestación tanto mediante el uso de medios públicos como privados - concertados y debidamente acreditados- Tales diferencias que encuentran también reflejo en los copagos de las prestaciones otorgadas: con carácter general los umbrales del copago se establecen entre la gratuidad, en función del nivel de rentas del beneficiario y conforme a unos baremos marcados en ocasiones por la propia comunidad o por las ordenanzas municipales concretas.

Es evidente que la continua disminución presupuestaria y falta de recursos destinados a la ayuda domiciliaria han supuesto el desbordamiento de un servicio altamente solicitado y que ha obligado a los poderes públicos a arbitrar fórmulas de complemento ante la necesidad de dar satisfacción a colectivos necesitados, ofertando servicios que de alguna forma actúan como "parches" en un precario sistema de atención al dependiente.

\section{Bibliografía}

ALEMÁN BRACHO, C.: "Los sistemas de servicios sociales en las Leyes autonómicas de servicios sociales", Revista Española de Derecho del Trabajo, núm. 152, 2011.

ALMEIDA CERRADA, M.: "Los desafíos de las políticas y de los servicios sociales municipales: de la superación de las secuelas de la Gran Recesión, a la adaptación a un nuevo entorno socioeconómico", Anuario del Gobierno Local, núm.1, 2017.

ARIAS MARTÍNEZ, Ma . A.: "Las competencias locales en materia de servicios sociales tras la aprobación de la Ley 27/2013, de 27 de diciembre, de racionalización y 
sostenibilidad de la Administración Local", Revista de Administración Pública, núm. 194, 2014.

BREZMES NIETO, Ma . J.: "El Sistema Público de Servicios Sociales 19 años después. Del plan concertado para las prestaciones básicas a la Ley de la Autonomía Personal", en AA.VV. (HIDALGO LAVIÉ, A. Coord): Trabajo social en el ámbito de la Ley de Promoción de la Autonomía Personal y atención a las personas en situación de dependencia: la profesión, la ley y los servicios sociales a debate, A Coruña (Netbiblo), 2011.

CARBONELL APARICI, G.J.: "Los derechos sociales en la Constitución española", Zerbitzuan: Gizarte zerbitzuetarako aldizkaria/ Revista de servicios sociales, núm. 70, 2020.

CAVAS MARTÍNEZ, F.: “Aspectos fundamentales de la Ley de promoción de la autonomía personal y atención a las personas en situación de dependencia", Aranzadi Social, núm. 13, 2006.

CERVERA, M., HERCE, J, LÓPEZ-CASASNOVAS, J, RODRÍGUEZ-CABRERO, G, y SOSVILLA, S.: Informe final del grupo de expertos para la evaluación del desarrollo y efectiva aplicación de la Ley 39/2006, 14 de diciembre, de Promoción de la Autonomía Personal y Atención a las Personas en Situación de Dependencia, 2009, IMSERSO.

CONDE MARÍN, E.: "La financiación de la dependencia: la financiación pública de la dependencia", en AA.VV. (MOLERO GARCÍA, Ma . L., Coord.): Retos para una implantación efectiva del sistema para la autonomía y atención a la dependencia, Madrid (Cinca), 2012.

CORDERO GORDILLO, V.: "Edad y discapacidad", en AA.VV. (CARDONA RUBERT, Ma B.; FLORES GIMÉNEZ, F.; Y CABEZA PEREIRO, J., Coords.): Edad, discriminación y derechos, Monografías Aranzadi, Cizur Menor (Thomson Reuters), 2019.

DURÁN BERNARDINO, M.: "La distribución constitucional y legal de competencias en el modelo de protección social a la dependencia", Aranzadi Social: Revista Doctrinal, vol. 6, núm.8, 2013.

FANTOVA AZCOAGA, F.: "Crisis de los cuidados y servicios sociales", Zerbitzuan, núm. 60, 2015.

GUTIÉRREZ RESA, A.: "El Plan Concertado de Prestaciones Básicas de Servicios Sociales en España (Once años de Plan Concertado)", Revista Española de Investigaciones Sociológicas, núm. 93, 2001.

HUBER, M. et allí.: "Expenditure and financing", en AA.VV.: Facts and figures on long-term care. Europe and North America, Viena (European Centre for Social Welfare Policy and Research), 2009.

HUETE GARCÍA, A., CHAVERRI CARBAJAL, A. y MORALES ROMO, N.: "El sistema para la autonomía y atención a la dependencia en España (SAAD). Memoria de debilidades desde su implantación", Prisma Social: Revista de Investigación Social, núm. $32,2021$. 
JIMÉNEZ LARA, A.: "El Sistema para la Autonomía y la Atención a la Dependencia”, Sociedad y Utopía. Revista de Ciencias Sociales, núm. 30, 2007.

LAS HERAS PINILLA, Ma . P.: "El sistema público de servicios sociales: contribución del trabajo social, desafíos, oportunidades y estrategias”, Trabajo Social Hoy, núm. extra.1, 2002.

MARTÍNEZ, M.F.; VILLALBA, C., y GARCÍA, M.: "Programas de respiro para cuidadores familiares”, Intervención Psicosocial, Vol. 10, núm. 1, 2001.

MONSERRAT CODORNIU, J.: "Sostenibilidad del sistema de atención a la dependencia”, Papeles de Economía Española, núm. 161, 2019.

ORTIZ WALS, V. y FERRERIRA LUZ, A.: "El Servicio de Ayuda a Domicilio como instrumento de Intervención Social con colectivos en riesgo de exclusión social", Documentos de Trabajo Social, núm. 49, 2011.

PISARELLO PRADOS, G.: Los derechos sociales y sus garantías: elementos para una reconstrucción, Madrid (Trotta), 2007.

PRADOS, C.: "Prevención y mantenimiento de la autonomía de los mayores: La ayuda a domicilio", Cuadernos de Trabajo Social, núm. 14 (Ejemplar dedicado a la vejez), 2001.

RAMÍREZ NAVARRO, J.M.: "La demolició controlada del Sistema d'Atenció a la Dependència, Revista de Treball Social, núm. 200, 2013.

REVUELTA ALONSO, M. ${ }^{a}$ L.: "La ayuda a domicilio como servicio de proximidad en el contexto social actual", Humanismo y Trabajo Social, Vol. 15, 2015.

RUIDÍAZ GARCÍA, C.: "La política social de atención a las personas dependientes en España. Balance y perspectivas de la Ley de dependencia”, REDUR 10, 2012.

SANCHO CASTIELLO, M. Y DÍAZ MARTIIN, R.: "Atención a las personas mayores en su entorno: teleasistencia, ayuda a domicilio y centros de día", Sociedad y Utopía. Revista de Ciencias Sociales, núm. 30, 2007.

SUBIRATS HUMET, J.: "El análisis de las políticas públicas", Gaceta sanitaria: Órgano oficial de la Sociedad Española de Salud Pública y Administración Sanitaria, Vol. 15, No. 3, 2001.

VELASCO CABALLERO, F.: "Nuevo régimen de competencias municipales en el Anteproyecto de Racionalización y Sostenibilidad de la Administración Local", Anuario de Derecho Municipal, 2012, núm. 6, 2013.

VIDA SORIA, J.: "Estudio preliminar sobre la recuperación de un clásico de la doctrina de la Seguridad Social”, incluido en la versión española, a cargo del propio autor del libro, DURAND, P.: La política contemporánea de Seguridad Social, Madrid (Ministerio de trabajo y Seguridad Social), 1991.

VILA LÓPEZ, L.: "Política social e inclusión social", Revista del Ministerio de Trabajo y Asuntos Sociales (ejemplar dedicado a Asuntos sociales), núm. 35, 2002.

YACEN ROJAS, K.: "Programas de respiro en el domicilio y acompañamiento a las personas cuidadoras primarias, una estrategia clave para humanizar la relación de cuidados en el ámbito familiar: el caso de Alkar Zaintzen”, Zerbitzuan, núm. 73, 2020. 


\section{Referencias normativas}

Ley 16/2019, de 2 de mayo, de Servicios Sociales de Canarias.

Ley 14/2010 de 16 de diciembre, de Servicios Sociales de Castilla-La Mancha.

Ley 16/2010, de 20 de diciembre, de Servicios Sociales de Castilla y León.

Ley 14/2015 de 9 de abril, de Servicios Sociales de Extremadura.

Ley 13/2008, de 3 de diciembre, de Servicios Sociales de Galicia.

Ley Foral 15/2006 de 14 de diciembre, sobre Servicios Sociales de Navarra.

Ley 1/2003 de 24 de febrero, de Servicios Sociales de Asturias.

Ley 3/2003 de 10 de abril, del Sistema de Servicios Sociales de Murcia.

Ley 11/2003 de 27 de marzo, de Servicios Sociales de Madrid.

Ley 2/2007, de 27 de marzo, de Derechos y Servicios Sociales de Cantabria.

Ley 12/2007 de 11 de octubre, de Servicios Sociales de Cataluña.

Ley 12/2008, de 5 de diciembre, de Servicios Sociales del País Vasco.

Ley 4/2009, de 11 de junio, de Servicios Sociales de las Illes Balears.

Ley 5/2009 de 30 de junio, de Servicios Sociales de Aragón.

Ley 7/2009, de 22 de diciembre, de Servicios Sociales de la Rioja.

Ley 9/2016 de 27 de diciembre, de Servicios Sociales de Andalucía.

Ley 3/2019, de 18 de febrero, de servicios sociales inclusivos de la Comunitat Valenciana.

Orden 7/2016, de 7 de abril, de la Vicepresidencia y Conselleria de Igualdad y Políticas Inclusivas, por la que se establecen las bases reguladoras de la concesión de subvenciones relativas al programa Bono Respiro y subvenciones para financiar estancias en centros de día para personas dependientes y en residencias de tercera edad.

Orden EMP/48/2009, de 24 de abril, por la que se desarrolla el catálogo de servicios del sistema para la autonomía personal y la atención a la dependencia y se regula la aportación económica de las personas usuarias en la Comunidad Autónoma de Cantabria.

Resolución de 9 de octubre de 2018, del Instituto de Mayores y Servicios Sociales, de delegación de la competencia sobre la gestión de la ayuda a domicilio básica y teleasistencia domiciliaria básica a la Ciudad de Ceuta.

Resolución de 9 de octubre de 2018, del Instituto de Mayores y Servicios Sociales, de delegación de la competencia sobre la gestión de la ayuda a domicilio básica y teleasistencia domiciliaria básica a la Ciudad de Melilla. 